sciendo

\title{
What Photographs Are (and What They Are Not)
}

Jiri Benovsky

University of Fribourg

Disputatio Vol. 4, No. 31

November 2011

DOI: $10.2478 /$ disp-2011-0011

ISSN: 0873-626X 


\title{
What photographs are (and what they are not)*
}

\author{
Jiri Benovsky \\ University of Fribourg
}

$\S 1$. For the metaphysician, photographs are very puzzling entities indeed. And even from the non-philosopher's intuitive point of view, it is not that clear what sort of thing a photograph is. Typically, if a client wants to purchase a photograph, she can mean very different things by 'buying a photograph' : she can mean to buy a print or a number of prints, or she can mean to buy a negative (when traditional film photographs are concerned) or a file (when digital photography is concerned), or she can mean to buy a right to use a photograph a precisely determined number of times in a number of brochures or on a website, and so on. When facing a new client, I always, without exception, face the problem of explaining to her what it is that she is actually buying - and it is not always clear that she is ever buying a photograph. As a metaphysician, I face a much more difficult challenge: find out to what ontological category photographs belong to. Are they concrete spatio-temporal entities like prints, are they universals since there can be many 'prints-instances' of a same photograph, are they sets or aggregates of prints, or something even different ? This is the task that I wish to undertake in this paper : examine all plausible metaphysical categories to which photographs could belong to, and see which one is the fittest. As we shall see, in this 'survival for the fittest' competition between traditional metaphysical categories, there will be no real winner : several categories will reveal themselves to be enlightening and useful when describing features of what photographs are, but none will prove to be entirely satisfactory. Photographs, it seems, are a sort of borderline entities

* I would like to thank Fabian Dorsch, Lynda Gaudemard, Mark Heller, Roger Pouivet and Ted Sider for discussions and helpful comments that helped me to improve this paper.

Disputatio, Vol. IV, No. 31, November 2011

Received on 5 October 2010 
that share some but not all aspects of several traditional metaphysical categories. Is it then justified to postulate a new ontological category to which photographs would properly belong ? On mainly methodological grounds, I shall argue that it is not, and I will suggest a different way out of this metaphysician's trouble by defending a nihilism about photographs. To put it bluntly, I will defend the claim that photographs do not exist - but I will also argue that this is not a very revisionary or anti-commonsensical claim.

§2. Let us get started with two basic premises about what sort of entities photographs are - these will be my desiderata that a metaphysical theory about the nature of photographs must be able to account for.

First, photographs can be seen - they are entities such that they can be visually perceived by normal human beings. This is of course only a necessary, not a sufficient condition, but it is an important one since for instance it immediately rules out the claim that photographs are mental entities. Indeed, as Levinson (1980, p. 63) rightly remarks about musical works, photographs as well as other artworks would become inaccessible and unshareable if they were 'private' mental entities, while it is part of our central conception of photographs that they can be seen by a number of different observers.

Second, photographs come into and go out of existence. Another way to put this is that they are created rather than discovered, they are human-made entities. As for the first desideratum, I take it that the justification for this second one lies in the fact that it is a deeply anchored and widely intuitively shared belief we have about photographs; besides it is also a well-defendable philosophical claim (see for instance Levinson $(1980,1991)$ about the parallel case of musical artworks $^{2}$ ) even if of course it has its objectors (see Kivy (1983)).

\footnotetext{
${ }^{2}$ In addition to his first-level reasons and arguments, Levinson (1991, p. 20) provides also this interesting meta-theoretical second-level justification : "There is, finally, another reason for trying to satisfy [the premise that musical works are created and come into and go out of existence] if we can, [...] namely the demands of theoretical unity. Since it seems incontestable that works in the fine arts and in a number of other arts as well are, as either physical objects or events [...], literally created, it seems perverse, if we can avoid it, to stick to a conception of musical (and perhaps literary) works that separates them from their fellows in the other realms of art. And all the more perverse where they are, when all is said and done, positive reasons to embrace the creatability condition. Shall paintings, drawings,
} 
Endorsing the opposite claim, namely that photographs somehow eternally exist without ever coming into and going out of existence, would lead to the conclusion that all photographs exist even before they are taken by a photographer, which teeters on the edge of absurdity.

Bearing these two desiderata in mind, let us now examine the process of production of photographs. Indeed, a photograph is the result of a process that involves various (types of) entities, as the following figures illustrate.
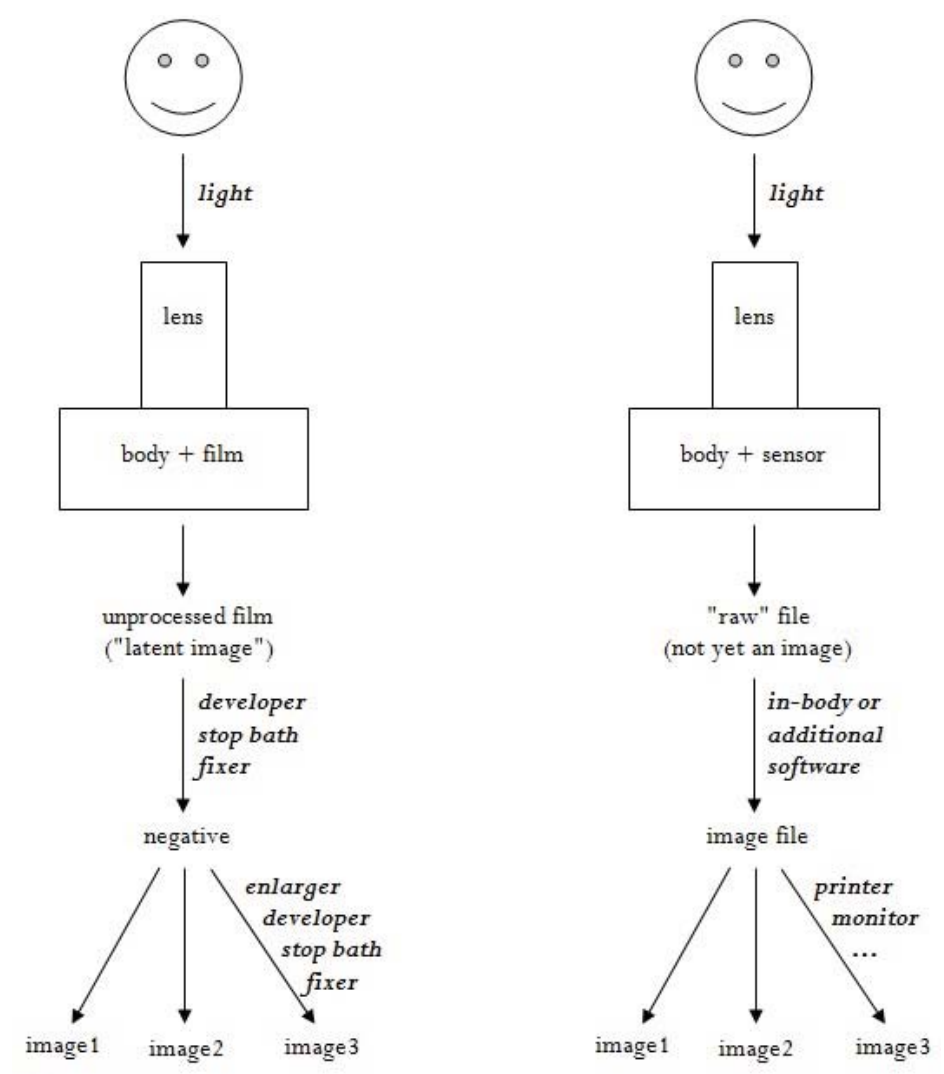

etchings, sculptures, palaces, dances, films, and so on all be truly creatable, in the full sense of the word, and only symphonies and novels denied this possibility ? There would be little profit, and false economy, in that." 
The figure on the left illustrates the typical and minimal process of production in traditional film photography, while the figure on the right illustrates the process of production in digital photography. I think it is important to emphasize that only at the end of the process, we have a photograph. Granted, there is a sense in which a photograph 'is already there' in former stages of the process of production (it is at least partly 'there' in the unprocessed film, in the negative, in the Raw file, or in the image file), but the entities involved in these stages (unprocessed film, negative, computer files) are not photographs since the process of production is not finished, and since none of these entities satisfies the desideratum of being visually perceivable by normal human beings. True enough, one can see an image if one looks at a negative (unlike the other three entities, where nothing at all is there to be seen), but it is not the photograph, it is an unfinished image whose colours, for instance, are not yet determined properly and will only be after a development process will have taken place. In some ways, such seeing of this unfinished photograph is a bit like seeing an unfinished painting. Thus, on the one hand, these four entities are not good candidates for being the photograph, but on the other hand, we could say that the photograph is there in a dispositional state. While I will not say that photographs are dispositions, we will see below that these stages of the process of production where the photograph 'is there as a disposition' do play a crucial role in the finding out of what ontological category photographs belong to.

Another way to emphasize the fact that it is only at the end of the process of production that a photograph comes into existence, is to insist on the dark room's tools and its digital counterparts to be essential parts of photographic systems. It would be a mistake to think that a photographic system is composed only of a lens and a camera body - rather, a photographic system genuinely does include various components that correspond to the stages of production of photographs such as chemicals, enlargers, software, printing devices, and so on. Without these tools no photograph could ever come into existence, and so it is only natural to claim them to be parts of any standard photographic system. As a bit special case, note that software used in digital photography can be actually built-in the body of the camera (and so the Raw file is processed there, which happens in the case of most amateur photographs - very often people who use this system are not even aware of there being two such stages involved since the process is fully transparent to the user), or it can be applied 
to the Raw file only later, using manual settings on a computer, and produce an image file only there (which happens in the case of most professional photographs, and parallels more closely the process of production of a traditional film photograph). The important thing is that, built-in or not, software (as its film photography counterparts in the dark room) is one of the essential components of a photographic system that is necessary in order to bring about the existence of a photograph.

There is a difference, though, between digital and film photography, that will show its importance below : Raw files and image files are much easier to duplicate and they can be duplicated without any loss of qualitative properties (without loss of information), whereas unprocessed films and negatives are very difficult to duplicate and always involve loss (and gain) of qualitative properties, thus not preserving qualitative identity. This is, of course, a matter of available technology : if we had at our disposal replicators like those used on Star Trek starships, we could as easily duplicate unprocessed films and negatives as we copy a computer file - but still, as photographic technology actually stands, there is such a difference between film and digital and it must be taken into account, which I will do in due course below.

$\S 3$. Given the two desiderata from the preceding section, and given that I claimed that it is only at the end of the process of production that there exists a photograph, it would seem now only natural to say that photographs belong to the ontological category of spatiotemporal material objects since they are prints (paper + ink) or computer screen images (arrangements of backlit liquid crystals, for instance). These can be seen, they come into and go out of existence in the way such concrete objects do, and they account for much of commonsense talk about photographs ("I carry photos of my loved ones in my wallet.").

Thus, the ontological category of concrete (material spatiotemporal) entities seems to account well for some central features of photographs - some, but not all. For photographs, typically, are repeatable. Although it can be the case that there exists only one print 
of a photograph, typically a photograph has a number of prints ${ }^{3}$. At this point, it may be suggested that photographs are sets or aggregates of all the prints, but such a claim cannot be satisfactory : first, sets are mathematical entities and as such are not there to be seen; second, one can destroy a set or an aggregate by destroying a member or a part of it while destroying one print does not destroy the photograph; third, this also holds the other way around since, as Rohrbaugh (2003) remarked, sets or aggregates are individuated by their members or parts and could not possibly have other, while a photograph can very well have more prints than it actually presently has.

So it seems that while the category of concrete entities does do some good work, it fails to account for the repeatability of photographs - that is, for photographs to have multiple instances, very much in a way universals have multiple instances. Perhaps then photographs are universals rather than concrete objects ? Such a suggestion is a widely discussed one, even if those who elaborate it mostly talk about "types" rather than universals (see Wolterstorff (1975), Levinson $(1980,1991)$ about the parallel case of musical artworks, and Kivy (1983)). Since a type is not an ontological category, I will stick in what follows to a discussion of the claim that photographs are universals.

The first distinction to be made is of course the one between platonic non-spatio-temporal universals and immanent spatio-temporal universals (à la Armstrong (1978)). If photographs were said to be platonic universals, it would become impossible to account for the second desideratum from $\S 2$ - such entities are not temporal and do not come into and go out of existence, and I take it that this is the main reason why photographs cannot belong to this ontological category. Besides, somewhat less importantly, such a view would make it less straightforward to meet the first desideratum as well : only instances of photographs could be actually seen, but not photographs themselves (I shall come back to this point below).

Thus, if photographs were to be universals, they would rather be immanent spatio-temporal armstrongian universals (I shall just say "universals" from now on). One of the core ideas about the nature of

\footnotetext{
${ }^{3}$ For simplicity, I will always speak about prints, but of course this also applies to computer screen images, or any other material spatio-temporal visually perceivable entity that can reasonably be taken to be a photographic image.
} 
such universals is that they exist iff they have an instance, which is highly relevant since it allows us to say that a photograph comes into existence when its first print is created, and then other prints can be created, and later if everything is destroyed (I shall say more on this later), the universal goes out of existence. This conception of universals also accounts for the fact that there is a good sense in which photographs are multiply spatio-temporally located which straightforwardly accounts for commonsensical claims such as "In my living room I have hung for display the same photograph you have in yours". Immanent universals thus posses some central features required to account for the metaphysical nature of photographs; most importantly for their repeatability. I shall now examine four objections to this view, and see what force they have.

Margolis (1980, p. 29) objects to such a view on the ground that if it were true we could never see a photograph, since we can never see universals. (And he shares the view that this is a desideratum that a theory about the nature of photographs should be able to satisfy.) Kivy (1983, p. 110) when speaking about musical artworks provides an answer, easily adapted to the case of photographs : by seeing a universal's instance, we see the universal itself.

Kivy's reply seems to me controversial, and unnecessarily strong in order to face Margolis' challenge. It is controversial because, at least prima facie, from the phenomenological point of view we see circular objects but we never see circularity and it would take a strong argument to be able to claim the contrary, an argument that Kivy does not provide. But most importantly, it is unnecessary to embrace such a strong claim. Any friend of universals will usually be happy, and rightly so, to claim that, granted, we never see circularity itself, but that we see circular things, and that's enough. Why would it be required to claim that we see circularity in order to say that it exists and that its existence accounts for claims of attribute agreement among circular things ? Friends of universals typically don't feel obliged to endorse any such strong claim, and when applied to the case of photographs they should feel exactly the same : namely, they could and should amend the first desideratum's claim and say that if photographs are universals, it is not necessary to require that a photograph must be visually perceivable, it is only required that instances of photographs should be visually perceivable. 
A different objection can be found in Dorsch (2007, p. 10). Dorsch does not explicitly speak about photographs, rather the target of his analysis are novels, but since novels are repeatables very much in a sense photographs are, his objection is easy to adapt. He says : "[...] novels have more fine-grained individuation conditions than types or kinds. Again, if two independently working authors write exactly the same sequence of sentences, their novels should still count as numerically distinct. But if the non-temporal types or kinds in question are not defined in terms of sequences of words, it is unclear in terms of which aspects of novels they might be specified instead".

In the case of photographs it seems perhaps even more natural to claim that if two photographers take two qualitatively exactly similar photographs, these should still count as two different photographs that are not the same universal. But it would become hard, on the universals view, to account for this distinction - universals are individuated by their qualitative nature in such a way that two instances of circularity or two instances of the exact same shade of red are by necessity instances of the same universal. Thus, I believe that the Dorsch objection stands.

There is I think an even stronger reason to reject the universals view. We have seen that an advantage of the immanent universals view is that it can account for the coming into and going of out existence of photographs. But it does not work quite as well as we could hope. Suppose I take a photograph using a digital photographic system and make two prints, so there exist two instances of it. Suppose then that I don't like it and destroy both prints by burning them. Did I make the photograph go out of existence ? If photographs were universals whose instances are visually perceivable entities such as prints, the answer should be affirmative - but it is not, since Raw files and image files remain, and any number of prints can easily be re-made using those (this is the 'dispositional aspect' of photographs that I already discussed above in $\S 2$ ). As long as there remain these entities where the photograph is in a sort of dispositional state, the photograph cannot genuinely be said to have gone of out existence - while the universal did, which shows that the universals view is not entirely adequate. To avoid this uncomfortable situation, the friend of the universals view could claim that entities like Raw files, image files, negatives, or unprocessed films also are instances of the photograph, but then we're back to the problem that is behind Dorsch's claim 
about novels : there is very little resemblance and no qualitative identity between entities like prints and entities like Raw files (or unprocessed films) and it would become really hard to defend the claim that these so qualitatively different entities are instances of the same universal.

Furthermore, for the same background reason, the universals view has difficulties even to account for the normal case where only prints are concerned, for even those are never exactly qualitatively identical due to technological reasons concerning imperfections of printing devices, computer monitors, and so on. Thus, even in the most straightforward case, it is not obvious for the universals view to account for the fact that, say, two prints are instances of the same universal, since they are not qualitatively identical (and sometimes are even qualitatively quite different).

In what I said above, I made use of what can be called "the test of destruction". Indeed, I think it is good methodology, when asking oneself what an entity $\mathrm{E}$ is, to look at what happens with $\mathrm{E}$ when some entities $\mathrm{X}, \mathrm{Y}, \mathrm{Z}$ are destroyed : if $\mathrm{E}$ is thereby destroyed then it very likely was identical with $\mathrm{X}, \mathrm{Y}, \mathrm{Z}$, and if $\mathrm{E}$ is not destroyed then it is something different. I have already hinted in several places above at how this methodological principle can be applied to the question of ontology of photographs; let me now sum this up and consider the standard case where we have a photograph taken using a traditional or a digital photographic system of which two prints were made. Obviously, if one of the prints is destroyed, the photograph was not destroyed since another print remains. As we have just seen above, even if both prints are destroyed, there still is a very good ('dispositional') sense in which the photograph was not destroyed - so, it does not seem correct to claim that a photograph is 'solely' a print, a set or aggregate of prints, or a universal of which the prints are instances. It seems that the entities (negatives, unprocessed films, Raw files, images files) where the photograph is in a sort of dispositional state somehow must play a crucial explanatory role in the ontological status and nature of photographs - but, it is true about these entities as well that even if they all were to be destroyed but prints were to remain, the photograph was not destroyed either. Thus, neither solely prints nor solely these other entities can be said to provide a full account of what photographs are - somehow 'a bit of both' is needed : if one truly wants to destroy a photograph, one has to de- 
stroy all prints, and negatives, unprocessed films, Raw files, and image files. What is the right conclusion to draw from this situation? Is it that a photograph is an entity that is somehow made of all these very different types of entities? If so, photographs would be bizarre entities indeed, dispositional and non-dispositional, visually perceivable and not visually perceivable, repeatable or not repeatable (in the case of unprocessed films). What an uncomfortable position to be in for a metaphysician!

$\S 4$. The conclusion that stems from arguments in $§ 2-3$ above is that traditional ontological categories like concrete objects, sets or aggregates of those, mental entities, platonic universals, immanent universals, or even dispositions are such that no one of them is satisfactorily able to account for the ontological status and nature of photographs. Simply put, photographs seem to share a bit of each category (except the category of mental entities and platonic universals) - each category has something interesting to say, but none is capable of saying it all. But how can this situation be handled by the metaphysician ? Are we to claim that photographs are some sort of trans-categorical entities? But how does that make sense?

One possible reaction to this situation is to postulate a new ontological category that has all the features that we need to account for the nature of photographs. This is the line that Rohrbauch (2003) takes and that Dorsch (2007) takes about novels as well. According to Dorsch, novels fall into a new category of "reproducible prototypes", while according to Rohrbauch (2003, p. 34-35) photographs are 'higher-level' non-physical continuants which stand in a relation of ontological dependence to causally-connected series of physical particulars. I will not discuss here the details of these interesting proposals, rather and I am at this stage more interested in their overall strategy. Indeed, I believe that such a way to face the uncomfortable situation we find ourselves in is methodologically mislead - it amounts to postulating a new ontological category, that is, a fundamental category of being, to account for something humans contingently did, and this does not seem right. Postulating an ontological category is a claim about the very structure of what there is at the most fundamental level, while photographs do not seem to be anything like some sort of basic and fundamental components of reality. Thus, introducing a new ontological category solely for the purpose of accounting for the 
nature of photographs seems to me methodologically (metatheoretically) ill-motivated.

Both Rohrbauch and Dorsch are sensitive to this worry, and both defend their strategy (their new ontological category) by trying to show that it can serve a wider purpose than just the one of solving a puzzle about ontology of photographs or novels. Dorsch, for instance, tries to show that his postulated category also accounts very well for the ontological status and nature of sounds, and Rohrbauch claims his new category to be useful to account for "novels, musical compositions, species of animals, clubs, sorts of artefact, and words of natural languages" as well (see Rohrbauch (2003, p. 35)).

If there is no good alternative, then maybe we should do what Rohrbauch and Dorsch recommend. But, only if we have no good alternative - and we do.

\$5. I will now claim that photographs do not exist. Furthermore, I will claim that this is not a very revisionary nor a very strong claim. I will then compare my nihilism about photographs to a more general nihilism about ordinary objects like tables or persons, à la Merricks (2001) or Heller (1990) ${ }^{4}$.

The simple idea behind my nihilism about photographs is that we already have all the entities we need without having to postulate photographs as sui generis entities. We have unprocessed films, we have negatives, we have Raw files, we have image files, we have prints, we have computer screen images, and so on. Importantly, all of these entities have a clear ontological status : they are concrete material objects with quite straightforward individuation conditions. Metaphysical worries arise only when we want to claim that in addition to all these things, there are photographs. But why should we feel the need to claim so ? Remember the troubles I mentioned at the beginning of this paper that I regularly have when a client wants to purchase a photograph : it is not always clear what exactly she wants to buy. Often, when asking to buy a photograph, she means to buy a print. Very often as well, she means to buy a computer file and the right to use it to make a determined number of prints, or to display it for a determined period of time on a website, and so on. Rarely, she

\footnotetext{
${ }^{4}$ Cameron (2008) defends a similar view about musical works.
} 
means to buy a negative or an unprocessed film. Never, she means to buy something that would not be a concrete object + a right to use it in a certain way ${ }^{5}$. This commercial behaviour shows how we ordinarily think about photographs : mostly in terms of prints, negatives or computer files. At no point in our ordinary understanding of photographs do we feel the need to appeal to any different sort of entities. Thus, our concept of a photograph simply (and often vaguely) supervenes on our concepts of metaphysically unproblematic ordinary material objects. My suggestion is that, as metaphysicians, we follow this ordinary way of understanding the nature of photographs. As metaphysicians as well as buyers, we do have all the entities we need, and we don't need to postulate entities of a new ontological category. Talk (not just ordinary talk but theoretical talk as well) about photographs can be easily paraphrased and understood as talk about one or more of the unproblematic entities available. Most importantly for art critics and aestheticians, the attribution of aesthetic properties to allegedly existing photographs does not create a problem. If I want to say how beautiful a photograph is, I am not attributing the aesthetic property to a negative, to an unprocessed film, or to a file - I am attributing it to some of the visually perceivable objects like prints or computer screen images. On purpose, in the preceding sentence, I said "some" - indeed, very often, when discussing the beauty of a photograph we can appreciate how better this print or this computer screen image looks than another (less well made) print or another computer screen image (displayed on a less well calibrated monitor). Thus, attributions of aesthetic properties only require the existence of these visually perceivable entities, and they often are attributions concerning one of those. They can, of course, also be attributions concerning a number of prints or even all existing prints of the same photograph (that is, all prints that are results of a process of production that contains the same unprocessed film or the same Raw file). Linguistically, such attributions then work exactly like well-known plural attributions such as "The USS Enterprise crew is very intelligent".

Neither does my nihilism force us to reject the two desiderata from $\S 2$. Granted, if photographs do not exist, they cannot be seen

\footnotetext{
${ }^{5}$ What ontological category rights belong to is a difficult question that falls outside the ambitions of this paper.
} 
and they cannot come into and go out of existence. But, as we have just seen, the core idea behind my nihilist claim is that for all practical and theoretical purposes we have all the entities we need : prints can be seen, computer images can be seen, and all of the entities involved in the process of production of these come into and go out of existence - thus, the two desiderata are easily taken as being about the nature of these entities, that (singularly or cumulatively) play the role of photographs for all purposes. Given my nihilism, strictly speaking, the desiderata have to be rejected of course since photographs don't exist, but the motivation behind these desiderata and the core idea they cherish are preserved.

A seeming - but only a seeming ! - of contradiction arises here on the linguistic level : on the one hand, I claim that it is false that photographs exist, while on the other I want to accept the truth of claims such as "There is a beautiful photograph hanging on the wall of my living room." Such two existential claims seem to be incompatible but they are not, because they are not uttered in the same language. Indeed, the former claim is a claim of Ontologese $e^{6}-$ a fundamental language of the metaphysician who recognizes that strictly speaking there are no entities such as photographs. The latter claim is a claim uttered in ordinary English where it can be unproblematically asserted that there is a photograph on the wall. To understand better the relationship between these two languages, let us consider more general forms of nihilism.

Indeed, my nihilism about photographs parallels, but does not entail nor require, a general nihilism about ordinary material objects. Such a more generalized view not only claims that we do not need to postulate photographs as sui generis entities but that we even do not need to postulate the existence of negatives, prints, files ... or even computers and photographic cameras, tables, clay statues, baseballs, and so on. A recent and well-developed defence of such nihilism can be found in Merricks (2001). The common idea to both eliminativist strategies about photographs and about, say, tables is that without having to postulate such entities, we already have all we need to account for all phenomena that need to be accounted for : we do not

\footnotetext{
6 "Ontologese" is Ted Sider's term. I am indebted to Ted Sider and Mark Heller for discussions that helped me write this paragraph; it is their strategy that I am using here.
} 
need photographs because we have prints, negatives, files, and so on, and we do not need tables because, as Merricks puts it, we have atoms $^{7}$ arranged tablewise. As I am now typing this sentence on my computer, it seems to me that I see a table in my visual field. But, as Merricks rightly claims, my visual experience would be exactly the same even if there were no table and if there were 'only' atoms arranged tablewise. Indeed, the visual experience I have is caused by light reflected by the atoms and this reflection would be exactly the same if there were a table. The idea here is that our sensory experiences can be accounted for in terms of some more basic and genuinely fundamental (and existing) entities, and so there is no need to postulate a further entity (a table). In the case of photographs, the analogous (but not exactly the same) claim is that the desideratum that photographs can be seen can be satisfied by realizing that our visual experiences of photographs can be accounted for in terms of prints (and computer screen images, ...), that is, in terms of entities of a genuinely fundamental ontological category, and so there is no need to postulate the existence of a further entity and a further ontological category. Were there to be photographs, our visual experiences would be exactly the same than experiences we actually have of prints. Were there to be tables, Merricks claims, our visual experiences would be exactly the same than experiences we actually have of atoms arranged tablewise. (Of course, the second desideratum - the coming into and going out of existence of photographs - cannot be accounted for by my nihilism about photographs, since the core of my thesis is precisely the denial of it. But of course, prints, files, negatives, ... do satisfy it perfectly well.)

This is not the place to defend full-blown general nihilism. So let me quickly mention, but not defend, some points that make it intuitively more acceptable. First, we have just seen that nihilism does not make us abandon our ordinary experience of the world, and that it is fully compatible with it. Second, as we have already seen above in the case of photographs, nihilism does not make us abandon ordinary language either. As Merricks sees it, rightly I think, the word "table" denotes a plurality of entities (a plurality of atoms) in the same sense

\footnotetext{
${ }^{7}$ Merricks does not have in mind democritean atoms, nor Bohr's atoms; rather he has in mind something like "fundamental particles" whatever they actually are. The atoms are "arranged tablewise" iff, if there were tables then they would compose a table.
} 
"the USS Enterprise crew" denotes a plurality of entities, rather than a single entity composed of the crew's members. The sentence "There are no tables" is then true when it is a sentence uttered in Ontologese, but this is compatible with the sentence "There is a table in my office" being true since it is a sentence in ordinary English. In Ontologese, it is true that there are atoms arranged tablewise in my office (that is, in 'atoms arranged officewise'), and this is all that is required for the ordinary English's sentence "There is a table in my office" to be true. This can simply be seen as a convention of ordinary English that whenever there are atoms arranged tablewise, it is true in ordinary English (but not in Ontologese) that there is a table .

I have not defended nor claimed the necessity of embracing a fullblown generalized nihilism. I have only quickly shown some parallels between this view and my much more modest claim that is only restricted to photographs. The core of my claim, if it were in need of being summarized in a slogan would go like this : photographs don't exist because we don't need them. Behind this slogan is hidden a meta-ontological principle of parsimony : only postulate the existence of entities when it is absolutely necessary. This principle has I think even more strength when applied not just to entities but to categories of entities : only postulate the existence of a fundamental ontological category (that shapes the very structure of being) when it is absolutely necessary. Claiming that it is necessary to do so because of the case of photographs is a much more mind-blowing move than endorsing eliminativism. So, unless it can be shown that photographs can be accounted for in terms of some genuinely fundamental ontological category, I suggest we are better off doing without them.

$$
\begin{array}{r}
\text { Jiri Benovsky } \\
\text { Department of Philosophy } \\
\text { University of Fribourg } \\
\text { Av. de l'Europe 20 } \\
1700 \text { Fribourg, Switzerland } \\
\text { jiri@benovsky.com } \\
\text { www.jiribenovsky.org }
\end{array}
$$

\footnotetext{
${ }^{8}$ Nihilism is then much less radical than it might seem. Furthermore, as the reader familiar with debates about vagueness and about material constitution knows, nihilism provides very powerful theoretical advantages in solving puzzles about vagueness, and puzzles about 'coincident entities' such as statues and lumps (see Merricks (2001, chap. 2, §II and §III)).
} 


\section{References}

ARMSTRONG, D. M. 1978. Nominalism and Realism. Cambridge University Press.

CAMERON, R. 2008. There are no things that are musical works. British Journal of Aesthetics 48:3, pp. 295-314.

DORSCH, F. 2007. Novel sounds. Manuscript, RERO digital library link : http: / / doc.rero.ch/record/11857

HELLER, M. 1990. The ontology of physical objects : four-dimensional hunks of matter. Cambridge University Press.

KIVY, P. 1983. Platonism in Music: A Kind of Defense. in The Worlds of Art and the World,

Grazer Philosophische Studien, 19:109-130.

LEVINSON, J. 1991. What a Musical Work Is, Again. in Music, Art, and Metaphysics, Cornell University Press, pp.215-263.

LEVINSON, J. 1980. What a Musical Work Is. Journal of Philosophy 77(1):5-28.

MARGOLIS, J. 1980. Art and philosophy. Humanities Press, New Jersey.

MERRICKS, T. 2001. Objects and Persons. Clarendon Press, Oxford.

ROHRBAUGH, G. 2003. Artworks as historical individuals. European Journal of Philosophy 11(2):177-205.

WOLTERSTORFF, N. 1975. Toward an Ontology of Art Works. Noûs 9:115-142. 